\title{
Production and Purification of Cutinase from Fusarium oxysporum Using Modified Growth Media and a Specific Cutinase Substrate
}

\author{
Ofir Degani1,2 \\ ${ }^{1}$ Tel-Hai College, Tel-Hai, Israel \\ ${ }^{2}$ Migal-Galilee Research Institute, Kiryat Shmona, Israel \\ Email: d-ofir@bezeqint.net, ofird@telhai.ac.il
}

Received 18 March 2015; accepted 1 April 2015; published 2 April 2015

Copyright (C) 2015 by author and Scientific Research Publishing Inc.

This work is licensed under the Creative Commons Attribution International License (CC BY). http://creativecommons.org/licenses/by/4.0/

(c) (i) Open Access

\begin{abstract}
Cutinases are hydrolytic enzymes used by phytopathogenic fungi to gain entry into plants by breaking down the cuticular barrier of higher plants. Cutinase displayed hydrolytic activity not only towards cutin, the main component of the plant cuticle, but also towards a variety of soluble synthetic esters, insoluble triglycerides and polyesters. Therefore, cutinase was evaluated for use in the chemical, food and cotton bio-scouring industry and for synthetic fibers modification. This research examined the production and purification of extracellular cutinase from the phytopathogenic fungus Fusarium oxysporum. The addition of apple cutin or its hydrolysate to the fungus growth medium resulted in an enhanced secretion of cutinase into the extracellular fluid. Testing 1-hexadecanol as an alternative to natural cutin to induce cutinase production resulted in a high process yield under modified growth conditions. Cutinase enzyme production was followed by an optimized purification method for enzyme preparation using high-performance liquid chromatography and high-specificity 4-nitrophenyl (16-methyl sulfide ester) hexadecanoate (pNMSEH) cutinase substrate. Electrophoresis sodiumdodecyl sulfate-polyacrylamide and isoelectric focusing gels enabled the final separation and identification of the protein. The purified cutinase had an approximate molecular weight of $20 \mathrm{kDa}$ and an isoelectric point of 4.7. The method presented here could be modified and used for cutinase production and purification in other microorganisms that exhibit cutinolytic activity.
\end{abstract}

\section{Keywords}

4-Nitrophenyl (16-Methyl Sulfide Ester) Hexadecanoate Substrate, Cutinase, Enzymes, Fusarium oxysporum, Media Optimization 


\section{Introduction}

Aerial parts of plants such as leaves, flowers, fruits and young stems are covered by cuticle [1]. The structural component of the plant cuticle is a biopolyester, cutin, derived from hydroxy and epoxy fatty acids [2]. Cutin is a lipid polymer, which is a relatively rigid meshwork of interesterified hydroxy and hydroxyl epoxy fatty acids, embedded in a layer of nonpolar lipids collectively called waxes. The fatty acids of cutin are usually $n-C_{16}$ and $\mathrm{n}-\mathrm{C}_{18}$, and contain one to three hydroxyl groups [3]. The actual composition of cutin is dependent on the species; however, in general, rapidly growing plants appear to contain the $\mathrm{C}_{16}$ acids predominantly, particularly dihydroxypalmitate, whereas in slower growing plants, a mixture of $\mathrm{C}_{16}$ and $\mathrm{C}_{18}$ acids is found [4]. The structure of cutin and the waxes largely determine the physical and chemical properties of the plant cuticle, which plays an important role in the interactions between the plant and its environment [5]. Cutin plays a key role in protecting against the entry of pathogens into plants, and its enzymatic degradation has proven to be one of the first steps in the infection process [6]. Some microorganisms, including plant pathogens, have been shown to live on cutin as their sole carbon source, and the production of extracellular cutinolytic enzymes has been shown [3].

Cutinase (E.C. 3.1.1.74) is an esterase that is the smallest member of the $\alpha / \beta$-hydrolase fold family, which is made up of other lipases [7]. Cutinase has been purified and characterized from several different sources, mainly fungi and pollen, but also bacteria [8]. The majority of the work has been done with a fungal pathogen of peas, Fusarium solani. f. pisi [9]. The production of cutinase seems to be highly regulated by growth conditions [10]. It is repressed by glucose and induced by cutin, hydrolyzed cutin or its major constituents [11]. Experiments with derivatives and analogues of $\omega$-hydroxy $\mathrm{C}_{16}$ acid indicated that a free hydroxyl group at the omega position was the most important factor determining the cutinase-inducing activity. Cutinase structure, function and biocatalytic applications were reviewed by Carvalho et al. [12] and recently by Chen et al. [8].

The versatility of cutinase with respect to a variety of possible substrates and its unique feature of being active regardless of the presence of an oil-water interface, makes them interesting as biocatalysts in several industrial applications [13] [14]. Non-aqueous enzymology has been one such area, where cutinase, like lipases, has proven to be an efficient biocatalyst for organic synthesis [15]. Cutinase versatility is exemplified by its efficiency in catalyzing triglyceride hydrolysis, esterification, and inter- and intra-transesterification reactions [13]. This activity profile gives it a number of important applications in industries ranging from dealing with detergents to foods and chemicals.

Due to the importance of the potential applications of cutinase, this enzyme has been cloned and expressed in Escherichia coli [16] and Saccharomyces cerevisiae [17]. Hydrolytic and synthetic reactions catalyzed by cutinase have potential use in the dairy industry for the hydrolysis of milk fat, in household detergents, in the oleochemical industry, in the synthesis of structured triglycerides, polymers and surfactants, in the synthesis of ingredients for personal-care products, in the synthesis of pharmaceuticals and agrochemicals containing one or more chiral centers, and in cotton bio-scouring and synthetic fibers modification [8] [13] [18] [19].

This work reports on the enhanced production of Fusarium oxysporum cutinase using modified growth media. The scientific research has focused on this pathogen as a candidate for cutinase production only in recent years, and its economic potential is now being gradually revealed [20]-[22]. The majority of studies had focused on the enhanced degradation and detoxification of phthalates using $F$. oxysporum cutinase. Phthalates are synthesized in massive amounts to produce various plastics and have become widespread in environments following their release as a result of extensive usage and production. This has been of an environmental concern because phthalates are hepatotoxic, teratogenic and carcinogenic by nature [23]. These works are part of the scientific effort focusing on using cutinase for environmental protection. Recent examples are the use of cutinase for biodegradation of environmental friendly plastics such as Poly (butylene succinate) (PBS) [24], aliphatic polyesters poly (e-caprolactone) (PCL) and foam plastic [25].

An important aspect of the commercialization of cutinase is the development of an efficient and low-cost production system that maximizes the biosynthesis of the heterologous protein while simplifying its recovery from the cultivation medium [21]. In this setting, one of the main drawbacks is the expensive, time-consuming and low yield process of producing cutin. The present work aimed at testing 1-hexadecanol as an alternative to natural cutin to induce cutinase production. This substance is easily obtained and in Fusarium solani f. sp. pisi results in a high process yield under modified growth conditions [6]. Cutinase enzyme production was followed by the optimized purification method for enzyme preparation using high-performance liquid chromatography (HPLC) analysis and a high-specificity 4-nitrophenyl (16-methyl sulfide ester) hexadecanoate (pNMSEH) cutinase substrate, described earlier [26]. 


\section{Materials and Methods}

\subsection{Preparation of Raw Apple Cutin and Hydrolysate of Apple Cutin}

Cutin was prepared from fresh apple fruits that were carefully selected to ensure that they have intact uninjured peels. The apples were washed thoroughly with double distilled water (DDW) and dried with paper towels. Each apple was dipped separately for $15 \mathrm{~min}$ in $200 \mathrm{ml}$ warm $\left(\sim 60^{\circ} \mathrm{C}\right)$ dichloromethane (rough extraction aimed for use in F. oxysporum growth medium) or hexane (delicate extraction aimed for use in gas chromatography/mass spectrometry analysis). The dichloromethane/hexane extraction collected from 10 - 20 apples was filtered, concentrated using a rotary evaporator (to remove the solvent) and kept overnight in a desiccator. The resulting dry cutin was collected, ground into powder and kept in a nitrogen atmosphere at $-70^{\circ} \mathrm{C}$ until use.

The preparation of cutin hydrolysate was done according to Lin et al. 1978 [6] with minor modifications. They determined that $100 \mu \mathrm{g}$ of cutin hydrolysate per ml was enough to induce cutinase synthesis. A total of 500 mg of apple cutin powder was suspended in $95 \%$ ethanol (30 ml) containing $10 \%$ (wt/vol) $\mathrm{KOH}$, and the suspension was refluxed overnight under a nitrogen atmosphere (added in advance for 30 min to the round-bottom flask) with a Soxhlet apparatus. The resulting mixture was acidified with concentrated $\mathrm{HCl}$, and the products were extracted three times repeatedly with chloroform in equal volume. The combined chloroform extract was filtrated using a Büchner funnel, evaporated to dryness under vacuum and kept in a desiccator for 16 h. The resulting hydrolysate was added to the $F$. oxysporum culture media to a final concentration, as indicated for each experiment.

\subsection{Cutinase Assay}

A cutinase assay based on a specific cutinase substrate, 4-nitrophenyl (16-methyl sulfone ester) hexadecanoate (pNMSEH), was used as described earlier [26]. This assay was validated and suggested as a substitute for traditional methods employing radioactive labeled cutin. Cutinase enzyme produced by Pseudomonas mandocino was obtained from InterSpex Products Inc. (California, USA), and carboxyl esterase (from porcine liver, E3019) was obtained from Sigma. Sodium phosphate buffer (300 $\mu \mathrm{l}, 100 \mathrm{mM}, \mathrm{pH}$ 8) was added to $5 \mathrm{mg}$ of pNMSEH substrate. Ten $\mu$ l of the F. oxysporum extracellular concentrated crude (see below) or cutinase enzyme (produced by P.mandocino, positive control) was added to the suspension, and the mixture, in a $1.5 \mathrm{ml}$ Eppendorf tube, was incubated in a rotary shaker at $37^{\circ} \mathrm{C}$ for $15 \mathrm{~min}$ or until color was developed. The samples were then centrifuged at 14,000 rpm for $15 \mathrm{~min}$, and the p-nitrophenol concentration was determined by measuring the absorbance at $405 \mathrm{~nm}$ with a Shimadzu spectrophotometer (UV-1601). One unit of cutinase is defined as the amount of enzyme required for the release of 1 micromole p-nitrophenol per ml per min.

\subsection{Esterase Assay}

Cutinase can also be measured spectrophotometrically by following the absorbance change at 405 nm, which indicates the release of p-nitrophenol (pNP) from p-nitrophenyl esters of short chain fatty acids used as model substrates [27]. Although this assay is simple, it does not distinguish between esterases and cutinases. Reaction mixture, in a $2 \mathrm{ml}$ Eppendorf tube, contained $100 \mu \mathrm{l}$ Triton ${ }^{\circledR}$ X-100 (non-ionic detergent, Sigma, 1 gr/250 ml DDW), $800 \mu$ l sodium phosphate buffer $(0.1 \mathrm{M}, \mathrm{pH}=8), 500 \mu \mathrm{l}$-nitrophenyl butyrate (pNPB, Sigma, $0.1 \mathrm{mM})$ and $100 \mu \mathrm{l} F$. oxysporum extracellular concentrated crude (see below) or cutinase enzyme solution (produced by P. mandocino, positive control) in a total volume of $1.5 \mathrm{ml}$. After the contents were mixed well, the hydrolysis was followed by measuring the absorbance at $405 \mathrm{~nm}$ at $37^{\circ} \mathrm{C}$ with a Shimadzu spectrophotometer (UV-1601). Initial linear rates (up to $20 \mathrm{sec}$ ) were used for calculating the rate of reaction (adopted from [27], with modifications). One unit of esterase is defined as the amount of enzyme required for the release of 1 micromole p-nitrophenol per ml per min.

\subsection{Protein Determination}

Protein concentration was measured using the Bio-Rad protein assay method according to the manufacturer's instructions. Briefly, a $800 \mu \mathrm{l}$ sample and a $200 \mu \mathrm{l}$ reagent were mixed and incubated for $10 \mathrm{~min}$ at room temperature. Absorbance was read at $595 \mathrm{~nm}$. A calibration curve was made using bovine albumin (sigma) at concentrations of $0-20 \mu \mathrm{g} / \mathrm{ml}$. 


\subsection{Isolation and Purification of Cutinase from Fusarium oxysporum}

F. oxysporum was maintained on potato dextrose agar (PDA) at $23^{\circ} \mathrm{C}$ for 10 days. Suspensions of mycelia in $10 \%$ glycerol $(2.5 \mathrm{ml})$ were added to $90 \mathrm{ml}$ mineral medium $(\mathrm{pH}=7.2$, described elsewhere, [6]) containing $0.1 \%$ glucose, and inoculated in a Fernbach flask for three days until the glucose in the medium was consumed. Then, $2 \mathrm{ml}$ inoculum from this preliminary culture was added to $250 \mathrm{ml}$ Erlenmeyer flasks containing 16 or $20 \mathrm{ml}$ mineral medium (prepared without glucose), and $100 \mathrm{mg}$ of raw apple cutin powder or $1.6 \mathrm{mg}$ of apple cutin hydrolysate or $200 \mathrm{mg}$ of 1-hexadecanol were added to induce cutinase secretion (the growth medium flasks were autoclaved prior to the insertion of the inoculum and cooled in a rotary shaker at $200 \mathrm{rpm}$ in order to suspend these non-soluble substances in the medium). The cultures were kept at $23^{\circ} \mathrm{C}$ and harvested 12 - 17 days later (after a peak in extracellular esterase/cutinase activity was measured). Each experiment was repeated two to three times.

For enzyme purification, the cultures were harvested on the $10^{\text {th }}$ growth day by filtration in a glass microfiber filter (90 mm diameter, Whatman, GF/C) and a $0.45 \mu \mathrm{m}$ filter using a Büchner funnel. In order to achieve higher concentrations of cutinase from the culture media, the release of the adhering enzyme was carried out by incubating the mycelium and cutin components with $10 \%$ methanol for $1 \mathrm{~h}$ and then treating it with sonication $(3 \times$ $30 \mathrm{sec}$, continuously). The resulting crude was concentrated by ultrafiltration with a 10-kDa cut-off type PM-10 membrane (Amicon Danvers Mass) (according to [6], with modifications).

The concentrated crude $(1 \mathrm{ml})$ in sodium phosphate buffer $(50 \mathrm{mM}$, pH 8$)$ was centrifuged $(14,000 \mathrm{rpm}, 2$ min) and purified in three steps in an HPLC (Waters 600E) equipped with a UV-VIS Spectra-Physics detector $(280 \mathrm{~nm})$ and a fraction collector (Pharmacia Biotech). The first cleaning step was done in a gel filtration Superdex 200 column (Pharmacia Biotech) with isocratic flow $(1 \mathrm{ml} / \mathrm{min})$ of sodium phosphate buffer (50 mM, $\mathrm{pH}$ 8), and fractions were collected every $1 \mathrm{~min}$ for $45 \mathrm{~min}$. The fractions that showed esterase activity were assayed for cutinase activity with the pNMSEH substrate and kept for the next cleaning step. The cutinase fractions were combined, concentrated in Amicon (PM-10 membrane), dissolved (Tris buffer, $50 \mathrm{mM}$, pH 8), centrifuged (14,000 rpm, 2 min) and injected into an anionic Mono Q column (FPLC, Pharmacia Biotech) with Tris buffer (50 mM, pH 8) and 0 - $1 \mathrm{M} \mathrm{NaCl}$ gradient for $40 \mathrm{~min}$. The fractions were analyzed as before, and those that exhibited cutinase activity were again combined, concentrated, dissolved, centrifuged and injected into the same column but with Tris buffer (50 mM, pH 9) and $0-0.5 \mathrm{M} \mathrm{NaCl}$ gradient for $40 \mathrm{~min}$. The cutinase fractions were separated on sodiumdodecyl sulfate (SDS)-polyacrylamide gel and an isoelectric focusing (IEF) gel (see below). The gel bands were examined for esterase and cutinase activity.

\subsection{Sodiumdodecyl Sulfate (SDS)-Polyacrylamide Gel}

Molecular weight estimation of polypeptide chains of the samples exhibiting cutinase activity was determined by one-dimension electrophoresis on SDS-polyacrylamide gels using a standard method [28]. A size marker, Sea Blue Plus 2 (4 - $250 \mathrm{kDa}$, Life Technologies, USA), was used to evaluate the proteins molecular weight. The proteins were separated using $50 \mathrm{~mA}$ voltages during $1 \mathrm{~h}$. Comassie brilliant blue staining of SDS-polyacrylamide gel (12\%) was used to view the proteins.

\subsection{Isoelectric Focusing (IEF) Gel}

Samples exhibiting cutinase activity were concentrated to about $20 \mu \mathrm{l}$ using a VectaSpin Micro from Whatman (cut-off $12 \mathrm{kDa}$ ) and run in triplicate on precast IEF gel (pH 5 - 8, Bio-Rad) at $100 \mathrm{~V}$ for $2 \mathrm{~h}$. For isoelectric point (pI) determination, an IEF broad standard marker (pI 4.45 - 9.6, Bio-Rad) was used. Two gels were used: one for protein staining and the other for esterase activity. Alternatively, the IEF gel (that includes the samples in triplicate) was cut into three parts. One part was stained for protein by incubation for 45 min in IEF gel staining as recommended by the manufacturer (BIO-RAD). Proteins were visualized in the gel after removing excess staining solution by de-staining with a solution of $40 \%$ methanol and $10 \%$ acetic acid.

The second part was stained for esterase activity (according to [29]). A total of $67 \mathrm{mg}$ of Fast Blue RR (sigma) was dissolved in $100 \mathrm{ml}$ sodium phosphate buffer $(50 \mathrm{mM}, \mathrm{pH} 7.4)$ and vacuum filtered with filter paper (Whatman 40). To this solution, $2.7 \mathrm{ml} 1 \% \alpha$-naphthyl acetate (in acetone) were added in the dark (the flask was wrapped using aluminum foil) and while stirring. This solution was used for incubating the gel at room temperature until clear bends appeared. A 7\% acetic acid solution in DDW was used to stop the reaction and reserve the gel. The third part was cut into 10 equal pieces, and each piece was incubated with pNMSEH cutinase sub- 
strate to test its cutinase activity. The gel pieces were incubated with the substrate for 20 min using a rotary shaker $(175 \mathrm{rpm})$ at $37^{\circ} \mathrm{C}$. The samples were centrifuged for $10 \mathrm{~min}$ at $14,000 \mathrm{rpm}$ and tested for absorbency at $405 \mathrm{~nm}$ with a Shimadzu spectrophotometer (UV-1601).

\subsection{Gas Chromatography/Mass Spectrometry Analysis}

Gas Chromatography/Mass Spectrometry analysis (GC/MS) was conducted as described before [18]. The raw apple cutin and hydrolysate of apple cutin samples were dried in a nitrogen atmosphere and silylated in $50 \mu \mathrm{L}$ of dioxane with $50 \mu \mathrm{L}$ of bis-(trimethylsilyl)-trifluoroacetamide for $30 \mathrm{~min}$ at $60^{\circ} \mathrm{C}$. Trimethylsilylated (TMS) derivatives were separated using a $0.25 \mathrm{~mm} \times 30 \mathrm{~m}$ HP5 Phe Me silicone column on a Hewlett-Packard 5972 series gas chromatograph with $\mathrm{He}$ as the carrier gas and detected with a Hewlett-Packard 5972 mass selective detector. The column was ramped at $10^{\circ} \mathrm{C} / \mathrm{min}$ from $150^{\circ} \mathrm{C}$ to $300^{\circ} \mathrm{C}$ and held for $20 \mathrm{~min}$. The injector and detector were set at $300^{\circ} \mathrm{C}$.

\section{Results}

In order to induce increased production of extracellular cutinase, we used the phytopathogenic fungus $F$. oxysporum that was grown on modified growth media (with restrict carbon source). Initially, changes in esterase activity, protein concentration and $\mathrm{pH}$ in the growth medium were measured during the growth of the fungi $F$. oxysporum on a medium containing raw apple cutin (Figure 1). In the presence of $100 \mathrm{mg}$ raw apple cutin powder, the extracellular esterase's activity was gradually increased, reaching a peak at day 12 of growth. This enzymatic activity elevation was accompanied by a corresponding increase in total extracellular protein content (Figure 1). Nevertheless, no changes in medium $\mathrm{pH}$ were observed, and a constant measure of $\mathrm{pH} 7.2$ was obtained.

The process of producing cutin is time-consuming and requires special attention to ensure that only the cutin layer is extracted during this procedure (see Materials and Methods). As an intermediate stage in the search for a substitute substrate, a hydrolysate of apple cutin was used. This substrate was prepared by ethanolic KOH solution digestion of the raw apple cutin, as described in Materials and Methods. GC/MS analysis of the raw apple cutin and hydrolysate extracts was performed to evaluate their composition. The components of both the raw and hydrolysate of apple cutin were identified by GC/MS analysis as saturated or derivatives of unsaturated fatty acid chains, mainly of C16:0, C18:0, C18:1 and C20:0 carbons (17\% - 19\%, 26\% - 30\%, 24\% - 30\% and 18\% 22\%, respectively, Table 1). This is in agreement with previous reports that n-C:16 and n-C:18 hydroxy-fatty

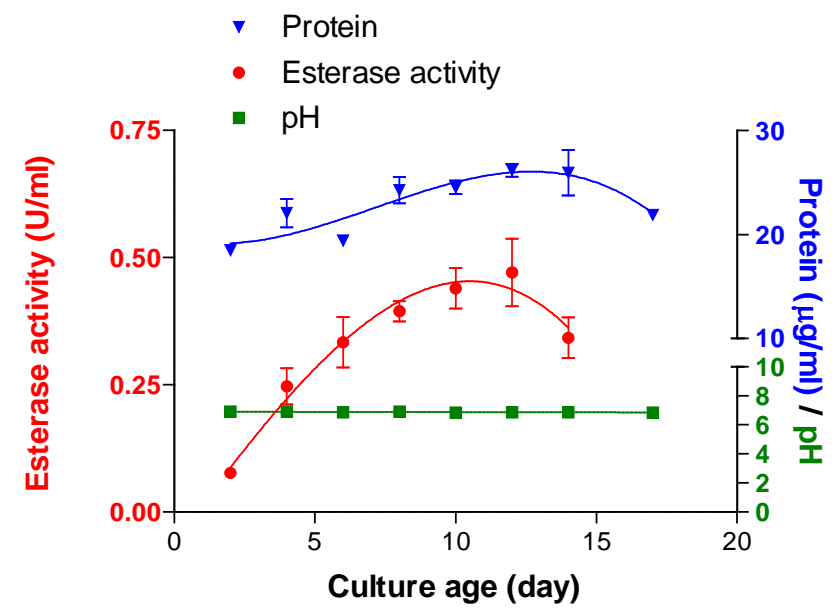

Figure 1. Changes in esterase activity, protein concentration and $\mathrm{pH}$ in the growth medium during the growth of the fungi Fusarium oxysporum on a mineral medium [6] containing raw apple cutin. Suspensions of the fungus mycelia (2.5 ml) were added to $90 \mathrm{ml}$ mineral medium containing $0.1 \%$ glucose and inoculated in a Fernbach flask for three days until the glucose was exhausted. Then, $2 \mathrm{ml}$ of the inoculum was added to a $250 \mathrm{ml}$ Erlenmeyer flask containing $16 \mathrm{ml}$ mineral medium containing $100 \mathrm{mg}$ raw apple cutin powder instead of glucose. The cultures were kept at $23^{\circ} \mathrm{C}$ without shaking. Values represent the average of three measurements. Bars indicate standard deviation. One unit of esterase is defined as the amount of enzyme required for the release of 1 micromole p-nitrophenol per ml per min. 
Table 1. Gas chromatography/mass spectrometry identification of the main components of waxes extracted from raw apple cutin and hydrolysate of apple cutin.

\begin{tabular}{ccccccc}
\hline \multirow{2}{*}{ Systematic Name } & Structural Formula & Lipid Numbers & \multicolumn{2}{c}{ Raw apple cutin } & \multicolumn{2}{c}{ Hydrolysate of apple cutin } \\
\cline { 3 - 7 } & & ppm & \% & ppm & \% \\
\hline Octanoic acid & $\mathrm{CH}_{3}\left(\mathrm{CH}_{2}\right)_{6} \mathrm{COOH}$ & $\mathrm{C} 8: 0$ & 27.1 & 7.5 & 0.0 & 0.0 \\
Tetradecanoic acid & $\mathrm{CH}_{3}\left(\mathrm{CH}_{2}\right)_{12} \mathrm{COOH}$ & $\mathrm{C} 14: 0$ & 7.3 & 2.0 & 0.0 & 0.0 \\
Hexadecanoic acid & $\mathrm{CH}_{3}\left(\mathrm{CH}_{2}\right)_{14} \mathrm{COOH}$ & $\mathrm{C} 16: 0$ & 68.7 & 18.9 & 32.4 & 16.8 \\
Octadecanoic acid & $\mathrm{CH}_{3}\left(\mathrm{CH}_{2}\right)_{16} \mathrm{COOH}$ & $\mathrm{C} 18: 0$ & 94.5 & 26.1 & 58.5 & 30.3 \\
N.a. & N.a. & C 18:1 & 87.4 & 24.1 & 58.9 & 30.5 \\
N.a. & N.a. & C 18:2 & 9.8 & 2.7 & 0.0 & 0.0 \\
Eicosanoic acid & $\mathrm{CH}_{3}\left(\mathrm{CH}_{2}\right)_{18} \mathrm{COOH}$ & $\mathrm{C} 20: 0$ & 65.1 & 17.9 & 43.1 & 22.3 \\
N.a. & N.a. & C 20:1 & 2.7 & 0.8 & 0.0 & 0.0 \\
\hline
\end{tabular}

*For unsaturated fatty acids, it was not possible to determine the precise formula and systematic name since few derivatives exist (depending on the location of the double bound in the carbons chain).

acids with hydroxyl groups in positions 1 and 3 were identified as the major apple and lime cutin monomers [30] [31].

When the apple cutin hydrolysate substrate was used in a reaction mixture together with commercial cutinase from $P$. mandocino, it caused a more rapid acidification of the reaction solution (as a result of the release of fatty acids-the substrate degradation products), in comparison to raw cutin (Figure 2). This enhanced activity was also reflected in faster reduction of the residual cutinase activity in the reaction solution (Figure 3) caused by a decrease in cutinase-specific activity over time in the presence of apple cutin hydrolysate substrate (Figure 4). It appears that this reduction in cutinase-specific activity is the consequence of its enhanced activity in the presence of this more accessible substrate. We therefore used this cutin hydrolysate instead of raw cutin as a sole carbon source in the growth medium of $F$. oxysporum and measured esterase activity (Figure 5). A peak in enzyme activity was measured on the $8^{\text {th }}$ growth day.

These results hinted to the advantage of using cutin's key components or their analogues in order to induce cutinase secretion to the growth medium. Such a component is the analogue of the cutin fraction, hexadecanols ( $\mathrm{C}_{16}$ alcohol) [6]. Indeed, the addition of $200 \mathrm{mg}$ 1-hexadecanol to the fungus growth medium resulted in an enhanced secretion of cutinase into the extracellular fluid in comparison to $100 \mathrm{mg}$ raw apple cutin powder (Figure 6). A peak in cutinase activity was measured at the $9^{\text {th }}$ growth day in both media. The enhanced cutinase expression in the presence of 1-hexadecanol was $17 \%$ (from 1.3 to $7.4 \mathrm{U} / \mathrm{ml}$ ).

The cutinase enzyme tends to form hydrophobic interactions with the $F$. oxysporum mycelium and the cutin components in the culture fluid. This led to low yield when extracting it from the medium. Thus, in order to achieve higher concentrations of cutinase from the culture media, the release of the adhering enzyme was carried out by rinsing the rough solid residues twice with $2 \mathrm{ml} 10 \%$ methanol and then several times with $2 \mathrm{ml}$ DDW each. This procedure successfully led to the release of the adhering enzyme to the rinsate, especially after the first rinsing that led to an over $17 \%$ elevation in enzyme activity in the rinsate (data not shown). Alternatively, the cultures were incubated with methanol (10\%) for $1 \mathrm{~h}$ as a sole treatment or in combination with sonication ( $3 \times$ $30 \mathrm{sec}$, continuously), as demonstrated in Figure 7. The combined treatment led to a very significant ( $>500 \%)$ increase in total protein and esterases activity measured in the rinsate (Figure 7).

The crude enzyme from the F. oxysporum culture extracellular fluid was purified with HPLC (Waters 600E) equipped with a spectra-physics detector $(280 \mathrm{~nm})$ and a fraction collector, and assayed for cutinolytic activity. The initial purification step of the extracellular cutinase was done with a Superdex 200 column, which is able to separate between proteins in a mass range of $10-600 \mathrm{kDa}$, with isocratic flow $(1 \mathrm{ml} / \mathrm{min})$ of potassium phosphate buffer ( $50 \mathrm{mM}, \mathrm{pH}$ 8). The fractions collected every $1 \mathrm{~min}$ (for $45 \mathrm{~min}$ ) were examined for esterase activity (with p-nitrophenyl butyrate) and cutinase activity (with the pNMSEH cutinase substrate) (Figure 8(a)). The fractions exhibiting cutinase activity (12 - $14 \mathrm{~min}$ ) were combined, concentrated by ultrafiltration, centrifuged and injected into an anionic Mono Q column (FPLC) with Tris buffer (50 mM, pH 8) and 0-1 M NaCl gradient for $40 \mathrm{~min}$. The fractions exhibiting cutinase activity (10 - $11 \mathrm{~min})$ were injected into the same anionic Mono Q 


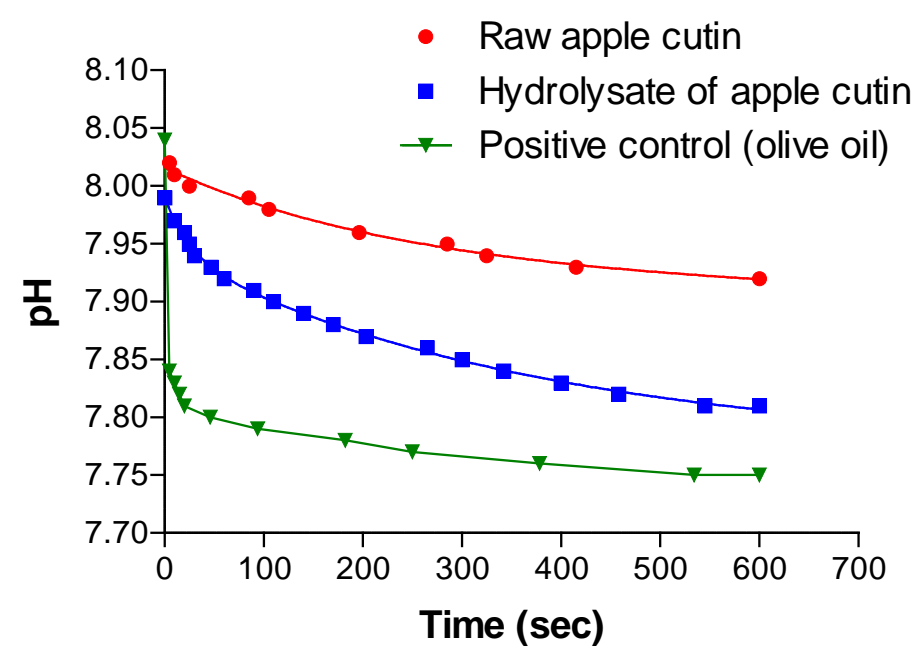

Figure 2. $\mathrm{pH}$ drop as a result of cutinase activity with various substrates. Twenty-five mg raw apple cutin or $1.4 \mathrm{mg}$ hydrolysate of apple cutin (prepared with hot alkaline ethanol-KOH in a reflux system) or $1.4 \mathrm{ml}$ olive oil (positive control) were incubated with $0.04 \mathrm{U} / \mathrm{ml}$ cutinase (produced by Pseudomonas mandocino obtained from Inter Spex Products Inc., California, USA) in 5 ml solution containing $0.04 \%$ Triton ${ }^{\circledR}$ X-100 and $20 \mathrm{mM}$ potassium phosphate buffer $\mathrm{pH}$ 8. The reactions were carried out at room temperature. The experiment was repeated three times, and all the results were the same as the one shown here.

$\checkmark$ Control

- Raw apple cutin

- Hydrolysate of apple cutin

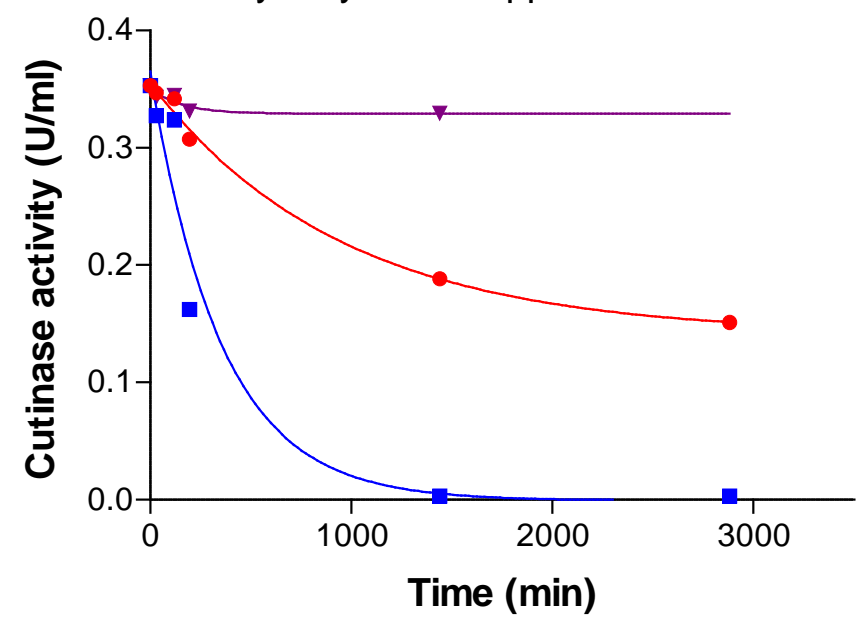

Figure 3. Reduction in residual cutinase activity in the presence of raw apple cutin and hydrolysate of apple cutin. $3.53 \mathrm{U} / \mathrm{ml}$ cutinase (produced by P.mandocino) were incubated with $50 \mathrm{mg}$ raw apple cutin or apple cutin hydrolysate in $5 \mathrm{ml}$ solution containing $100 \mathrm{mM}$ potassium phosphate buffer, $\mathrm{pH} 8$ and $0.04 \%$ Triton ${ }^{\circledR} \mathrm{X}-100$ at $37^{\circ} \mathrm{C}$. The control test tube was incubated under the same conditions with no substrate. Cutinase residual activity was measured at the indicated time using specific cutinase substrate, 4-nitrophenyl (16-methyl sulfone ester) hexadecanoate (pNMSEH) [26]. Values represent the average of two independent replications. One unit of cutinase is defined as the amount of enzyme required for the release of 1 micromole p-nitrophenol per ml per min.

column, but this time in $\mathrm{pH} 9$ Tris buffer $(50 \mathrm{mM})$ and 0 - $0.5 \mathrm{M} \mathrm{NaCL}$ gradient for 40 min. Figure 8(b) illustrates the Mono Q (pH 9) purification of fraction 10 from the former step, which had the highest specific activity yield and purification degree (see Table 2). The Superdex 200 and anionic Mono Q (pH 8) columns purification steps for the cutinase from F. oxysporum (esterase assay with p-nitrophenyl butyrate), including total protein, total activity, specific activity, yield and purification degree, are presented in Table 2. These three purification 


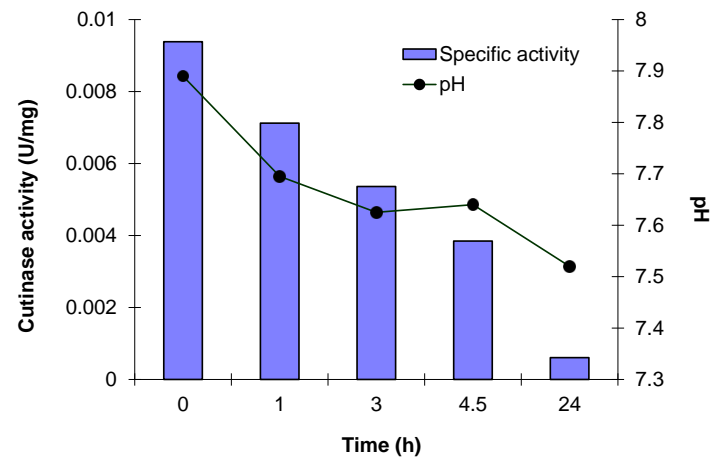

Figure 4. Changes in $\mathrm{pH}$ values of the solution and cutinase specific activity over time in the presence of apple cutin hydrolysate substrate. Cutinase ( $3.53 \mathrm{U} / \mathrm{ml}$, produced by $P$. mandocino) was incubated with $1.4 \mathrm{mg}$ cutin hydrolysate at $37^{\circ} \mathrm{C}$ in $5 \mathrm{ml}$ solution containing $20 \mathrm{mM}$ potassium phosphate buffer, $\mathrm{pH} 8$ and $0.04 \%$ Triton ${ }^{\circledR} \mathrm{X}-100$ for the indicated times. Values represent the average of two independent replications. Cutinase activity unit definition is as in Figure 3.

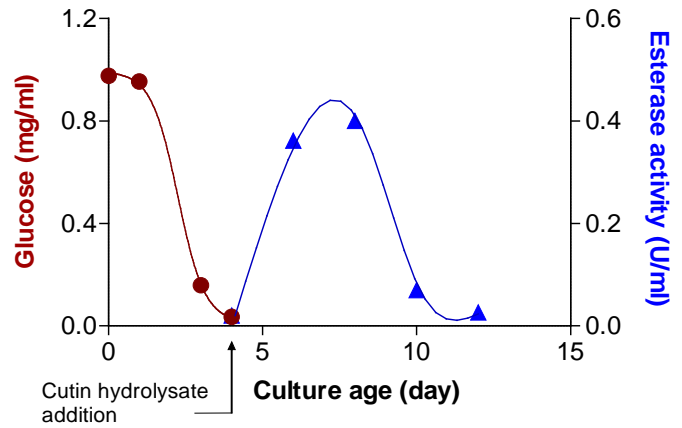

Figure 5. Esterase activity in the growth medium of $F$. oxysporum growing on a cutin hydrolysate as a sole carbon source. Stationary shallow cultures of the fungus grew for 4 days at room temperature $\left(25^{\circ} \mathrm{C}\right)$ in 250 ml Erlenmeyer flasks containing $20 \mathrm{ml}$ mineral medium and $0.1 \%$ glucose. On the fourth day, when the glucose in the medium was consumed, $1.6 \mathrm{mg}$ apple cutin hydrolysate was added to each flask. Values represent the average of two independent replications. Esterase activity unit definition is as in Figure 1.

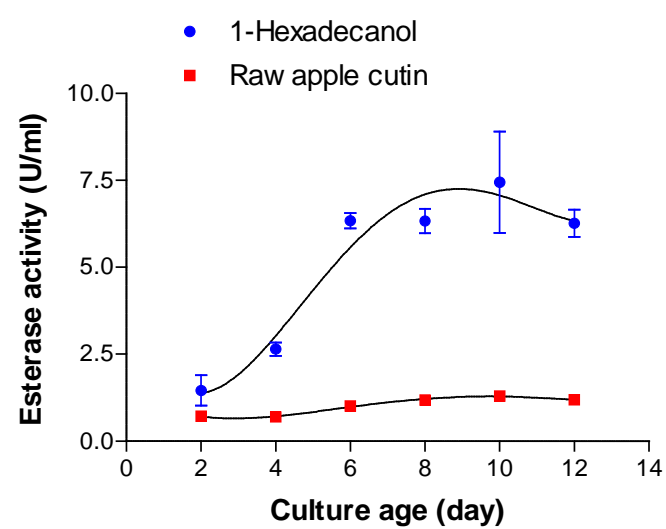

Figure 6. Effect of 1-hexadecanol on esterase activity measured in the F. oxysporum culture medium. Fungal colonies were grown on $20 \mathrm{ml}$ mineral medium containing $0.1 \%$ glucose (as in Figure 1 ) for 4 days until the glucose in the medium was consumed. Then, $2 \mathrm{ml}$ inoculum from this preliminary culture was transferred to $250 \mathrm{ml}$ Erlenmeyer flasks containing $20 \mathrm{ml}$ mineral medium and $100 \mathrm{mg}$ raw apple cutin powder or $200 \mathrm{mg}$ 1-hexadecanol.When 1-hexadecanol was used as a carbon source, the flasks were autoclaved prior to the insertion of the inoculum and cooled in a rotary shaker at $200 \mathrm{rpm}$ after the addition of $0.5 \%$ Tween 80 in order to suspend the 1-hexadecanol in the medium. The shallow cultures were grown at $23^{\circ} \mathrm{C}$ without shaking for 12 days. Values represent the average of three measurements. Bars indicate standard deviation. Esterase activity unit definition is as in Figure 1. 


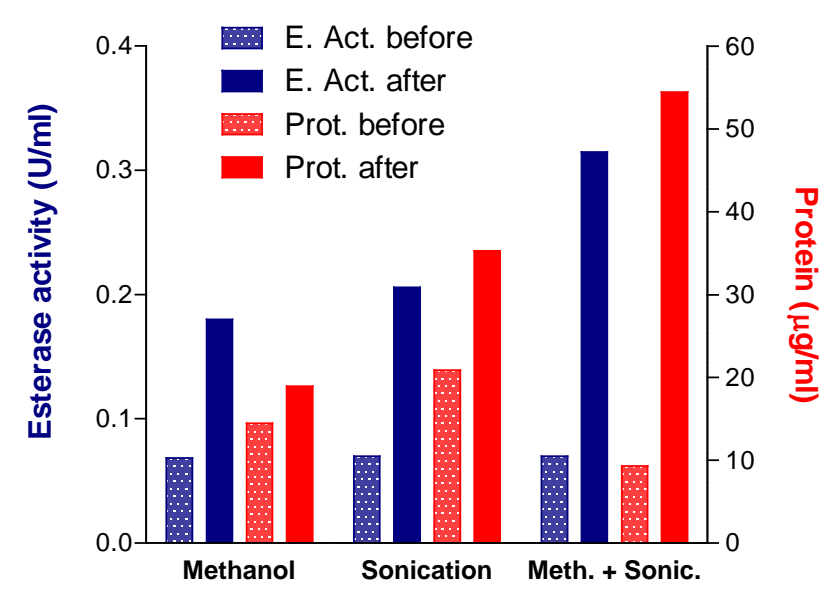

Figure 7. Effect of methanol $(10 \%)$ and sonication $(3 \times 30 \mathrm{sec}$, continuously) on the separation of the adhering cutinase from the $F$. oxysporum mycelium and from the cutin components in the culture fluid. The cultures were grown in $20 \mathrm{ml}$ mineral medium, as described in Figure 1 and harvested on the $10^{\text {th }}$ growth day by filtration using a Büchner funnel with a glass microfiber filter (90 mm diameter, Whatman, GF/C). The mycelium and cutin components were incubated with the methanol (Meth.) for $1 \mathrm{~h}$ and/or treated with sonication (Sonic. $3 \times 30 \mathrm{sec}$, continuously). Values represent the average of two measurements of protein (Prot.) and esterase activity (E. Act.) conducted before and after each treatment. Esterase activity unit definition is as in Figure 1.

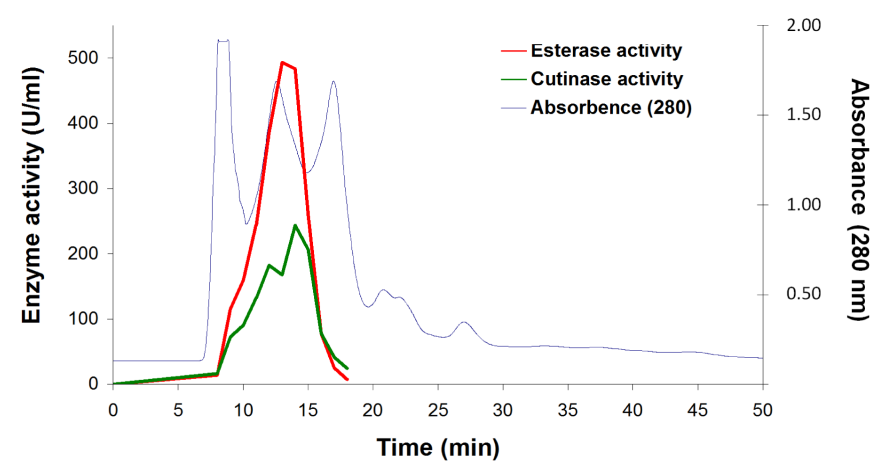

(a)

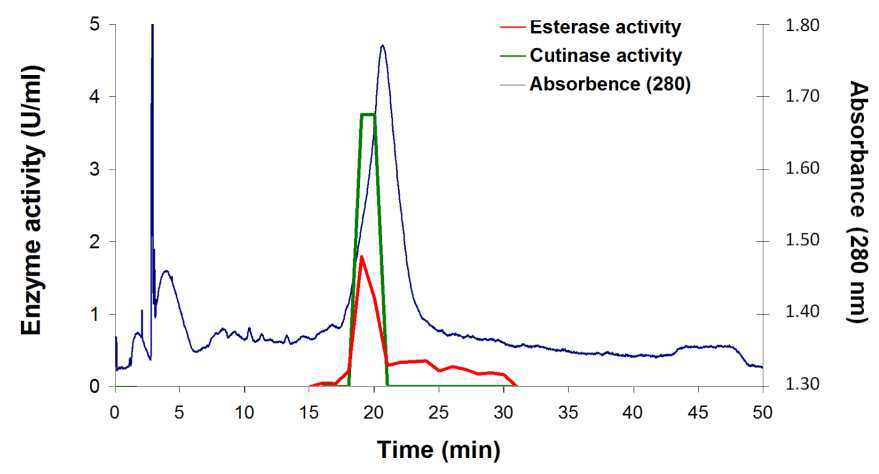

(b)

Figure 8. (a) High Pressure Liquid Chromatography (HPLC) first and last purification steps for the cutinase enzyme from Fusarium oxysporum. Purification was done with an HPLC (Waters 600E) equipped with a spectra-physics detector (280 $\mathrm{nm}$ ), a fraction collector (Pharmacia Biotech). (a) First step of cutinase purification using gel filtration Superdex 200 column with isocratic flow (1 ml/min) of potassium phosphate buffer (50 mM, pH 8). Fractions were collected every 1 min for 45 min. The fractions exhibiting esterase activity (with p-nitrophenyl butyrate) were also assayed for cutinase activity with the pNMSEH substrate. (b) Final step of cutinase purification using Mono Q column (pH 9). The fractions enriched with cutinase activity were injected into the Mono Q column with Tris buffer (50 mM) pH 9 and 0 - $0.5 \mathrm{M} \mathrm{NaCL}$ gradient for 40 min. Esterase and cutinase activity unit definitions are as in Figure 1 and Figure 3, respectively. 
Table 2. Purification steps for cutinase from Fusarium oxysporum (esterase assay with p-nitrophenyl butyrate).

\begin{tabular}{cccccccc}
\hline Description & $\begin{array}{c}\text { Volume } \\
\text { (ml) }\end{array}$ & $\begin{array}{c}\text { Activity } \\
\text { (U/ml) }\end{array}$ & $\begin{array}{c}\text { General } \\
\text { activity (U) }\end{array}$ & $\begin{array}{c}\text { Yield } \\
(\mathbf{\%})\end{array}$ & $\begin{array}{c}\text { Protein } \\
\text { (mg/ml) }\end{array}$ & $\begin{array}{c}\text { Specific activity } \\
\text { (U/mg) }\end{array}$ & $\begin{array}{c}\text { Purification } \\
\text { (fold) }\end{array}$ \\
$\begin{array}{c}\text { Crude } \\
\text { extract }\end{array}$ & 3 & 550 & 1374 & 100 & 14 & 40 & 1 \\
$\begin{array}{c}\text { Superdex 200 } \\
\text { mono Q pH = 8 } \\
\text { (fraction 10) }\end{array}$ & 2 & 218 & 437 & 32 & 3 & 85 & 2.1 \\
\hline
\end{tabular}

* One unit of esterase is defined as the amount of enzyme required for the release of 1 micromole p-nitrophenol per ml per min.

steps led to an increase in enzyme-specific activity and yield together with a markedly higher purification degree. A yield of 7\% cutinase activity, of the initial extract, was obtained after the Mono Q column step (with Tris buffer $\mathrm{pH}$ 8) and the specific activity was elevated 6.9 fold, from $40 \mathrm{U} / \mathrm{mg}$ to $274 \mathrm{U} / \mathrm{mg}$.

Samples from the three purification steps were analyzed using SDS-PAGE and IEF (Figure 9), and the molecular weight of the purified enzyme was estimated based on protein standards used as molecular weight markers. The cutinase protein band was already clearly identified in the crude (Figure 9(a)). Further purification revealed that from the extracellular fluid of $F$. oxysporum cultures, a cutinase with a molecular weight of about 20 $\mathrm{kDa}$ and an isoelectric point of 4.7 were isolated (Figures 9(b)-(c)).

A higher molecular weight (about $60 \mathrm{kDa}$ ) protein with an isoelectric point of about 5.3 having esterase activity and a low specific cutinolytic activity was also detected in the extracellular fluid of $F$. oxysporum (Figure 9(b)). This is most likely a nonspecific esterase such as those produced by F. solani. f. pisi. [32], Fusarium roseum f. sp. Culmorum [33] and Colletotrichum lagenarium [34] when grown on cutin as the sole carbon source. For final confirmation of the segment exhibits cutinase activity, the first two purification step samples were loaded in triplicate on a new IEF gel. After the separation, the gel was cut into three strips, one of which underwent protein staining, the second was stained for esterase activity and the third was cut into 10 equal pieces, and each piece was incubated separately with the pNMSEH cutinase substrate. The results reveal a dominant band of protein (No. 8) that shows esterase and cutinase activity (Figure 9(c)).

\section{Discussion}

Cutinases are hydrolytic enzymes that have substantial potential to be used widely in food, chemical, detergent, environmental and textile industries [8] [14]. Since the development by Purdy and Kolattukudy [32] of an assay for cutinase activity with radio-labeld cutin as substrate, it has been possible to confirm that numerous fungi can grow on cutin and synthesize cutinase [4] [8]. Like other fungi, F. oxysporum can grow on cutin or other carbon sources on liquid culture [21]. Nevertheless, the fungal strain, substrate selection, culture conditions and extraction methods may influence the yield of cutinase production dramatically.

The aim of this study was to optimize these varieties as part of the continuous scientific effort to establish the production and use of cutinase for biotechnology purposes. Moreover, the search for cutinase inducers other than cutin, which is expensive and difficult to obtain on a large scale, is an important step when considering the viability of industrial fermentation for the preparation of fungal cutinases for commercial applications. Cutin or cutin hydolisate from apple fruit and a $\mathrm{C}_{16}$ alcohol (1-hexadecanol) were used to induce cutinolytic esterase activity during saprophytic growth of $F$. oxysporum (Figure 1, Figure 5, Figure 6). A similar technique was used to evaluate other phytopathogens for their potential use for cutinase production [35]. Indeed, these substrates cause a peak on day 8 - 12 (some variations occur depending on the carbon source) of growth in the cutinase production, measured by a specific, recently developed pNMSEH cutinase assay [26].

Purdy and Kolattukudy [36] reported that the F. solani. f. pisi. extracellular cutinase induced by apple cutin reached its highest levels after 12 days of growth. More recently, Macedo and Pio [37] reported that the best conditions for the production of $F$. oxysporum extracellular cutinase were observed in a fermentation medium containing $1 \%$ cutin (w/v) incubated for 12 days at $30^{\circ} \mathrm{C}$ and $100 \mathrm{rpm}$. The use of cutin hydrolysate was first demonstrated by Lin and Kolattukudy [6]. They found that in F. solani. f. pisi., a low level (up to $100 \mathrm{\mu g} / \mathrm{ml}$ ) of chemically prepared cutin hydrolysate was shown to induce cutinase production in glucose-grown fungi. Our results support this report. Interestingly, a different induction mechanism may exist in bacteria since they lack glucose catabolite repression and the induction of the enzyme by cutin hydrolysate [11]. 


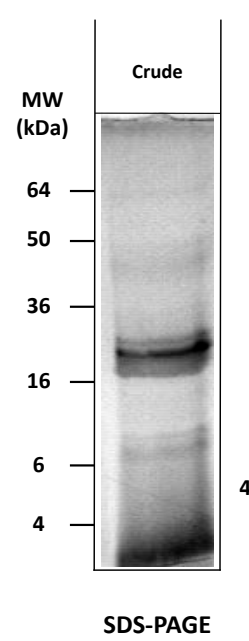

(a)

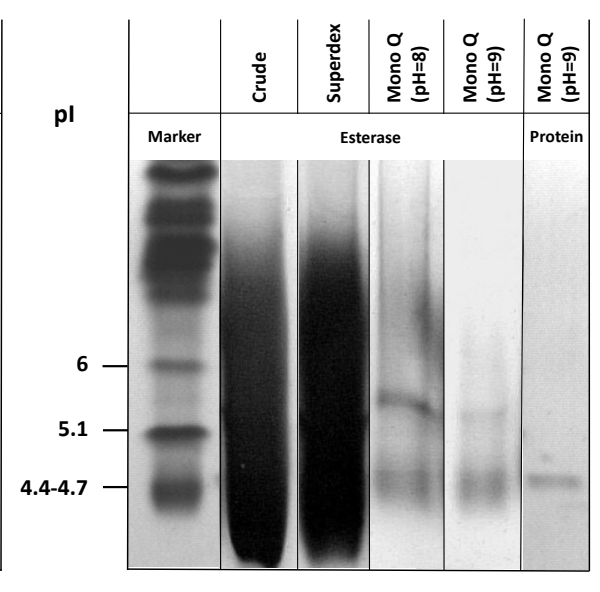

IEF

(b)

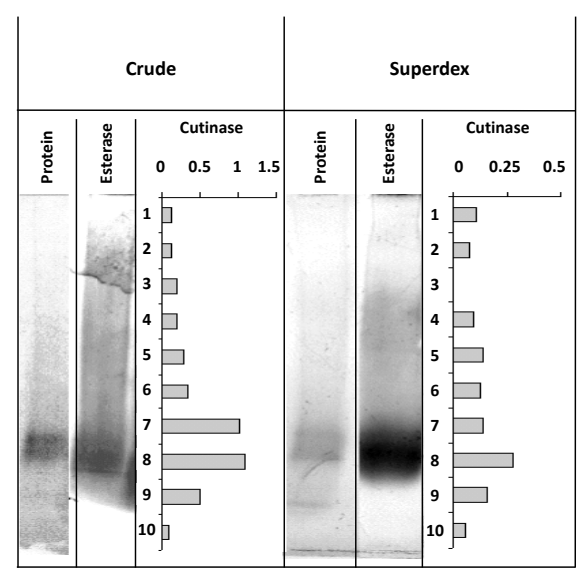

IEF

(c)

Figure 9. Sodiumdodecyl sulfate (SDS)-polyacrylamide gel and isoelectric focusing (IEF) purification steps of cutinase from F. oxysporum. (a) Comassie blue staining of the crude enzyme SDS-polyacrylamide gel (12\%). Size marker, Sea Blue Plus 2 (4 - 250 kDa, Life Technologies, USA), was used to evaluate the protein's molecular weight (MW). (b) An IEF separation of the F. oxysporum cutinase purification steps. The gel was stained for esterase activity (left) and protein (right). (c) Another IEF gel (that includes the first two purification step samples loaded in triplicate) was cut into three parts. One part (left) was stained for protein as recommended by the manufacturer (BIO-RAD), the second part (middle) was stained for esterase activity (according to [29]), and the third part (right) was cut into 10 equal pieces, and each piece was incubated with pNMSEH cutinase substrate to test its cutinase activity, as described in the Materials and Methods. Cutinase activty units are U/ml and the activity unit definition is as in Figure 3.

Adding 1-hexadecanol to the growth medium of $F$. oxysporum as a sole carbon source proved to be an excellent trigger for cutin hydrolase extracellular activity (Figure 6). It represents a potential low-cost inducer in industrial fermentations for the preparation of microbial cutinases for commercial applications. The fatty acids of cutin are usually $n-\mathrm{C}_{16}$ and $\mathrm{n}-\mathrm{C}_{18}$ and contain one to three hydroxyl groups. Lin and Kolattukudy [6] suggested that the hydroxyl group at the $\omega$-carbon of 16-hydroxypalmitic acid is the most important factor determining the cutinase-inducing activity of the monomer; the carboxyl group does not appear to be significant for this purpose. Moreover, they reported that hexadecanol, which represents the replacement of the carboxyl group by hydrogen, was just as effective as $\omega$-hydroxypalmitic acid in inducing cutinase. This is also the case for $F$. oxysporum, as demonstrated here.

Cutinases have a molecular weight around 22,000 daltons with highly conserved stretches, which include four invariant cysteines, forming two disulfide bridges [38]. The results found in this work show that the F. oxysporum cutinase active band $(20 \mathrm{kDa})$ is well within the size range of other purified cutinases [4]. Previously it has been shown that fungal cutinases catalyze the hydrolysis of $p$-nitrophenyl esters of $\mathrm{C}_{4}$ to $\mathrm{C}_{16}$ fatty acids, resulting in a general trend of increasing $K_{\mathrm{m}}$, and decreasing $V_{\max }$ [39]. As the chain length of the acyl moiety increased from $C_{2}$ to $C_{12}$, the $V_{\max }$ of many fungal cutinases decreased 200-1,000-fold. More recently, the biochemical characterization properties (including catalytic characteristics) of cutinases produced by Fusarium oxysporum in four different culture media against a panel of substrates was demonstrated by Speranza et al. [40]. Their study included testing the purified enzyme for cutinolytic activity by replacing the p-nitrophenyl butyrate (p-NPB, 4C) in the reaction, also described in our work, by different substrates (chain length), such as p-nitrophenylcaprilate (p-NPC, 8C), p-nitrophenyllaurate (p-NPL, 12C) and p-nitrophenylpalmitate (p-NPP, 16C). The enzyme had higher specificity for short and medium chain fatty acids, and the activities toward long-chain pNP-fatty acids were low. The substrate specificity of the purified cutinase from $F$. oxysporum against the specific pNMSEH was evaluated qualitatively (Figure 9). Testing the purified enzyme for cutinolytic specific activity against the pNMSEH and other new substrates should be the aim of a follow-up study.

\section{Conclusion}

The phytopathogenic fungus $F$. oxysporum has been suggested in recent years to be a promising candidate for 
cutinase production due to its abundance and to the success in using its cutinase for the degradation and detoxification of phthalates [23]. This research examined the production and purification of extracellular cutinase from $F$. oxysporum. We demonstrated that the addition of apple cutin, its hydrolysate and especially 1-hexadecanol to the fungus growth medium resulted in an enhanced secretion of cutinase into the extracellular fluid. The crude enzyme was purified using HPLC followed by SDS-PAGE and IEF. The resulting purified protein was identified using pNMSEH, a specific cutinase substrate, and characterized to have a molecular weight of $20 \mathrm{kDa}$ and an isoelectric point of 4.7. The detailed method presented here can be generalized and used for the screening of microorganisms for the production of cutin-degrading enzymes and for the production and purification of this biotechnologically important enzyme.

\section{Acknowledgements}

I would like to thank Prof. Carlos G. Dosoretz (Technion-Israel Institute of Technology, Israel) very much for his guidance, support and helpful advice. I am also grateful to Prof. Shimon Gepstein (Technion-Israel Institute of Technology, Israel) for his many helpful suggestions.

\section{References}

[1] Yeats, T.H. and Rose, J.K. (2013) The Formation and Function of Plant Cuticles. Plant physiology, 163, 5-20. http://dx.doi.org/10.1104/pp.113.222737

[2] Domínguez, E., Heredia-Guerrero, J.A. and Heredia, A. (2011) The Biophysical Design of Plant Cuticles: An Overview. New Phytologist, 189, 938-949. http://dx.doi.org/10.1111/j.1469-8137.2010.03553.x

[3] Purdy, R. and Kolattukudy, P. (1975) Hydrolysis of Plant Cuticle by Plant Pathogens. Purification, Amino Acid Composition, and Molecular Weight of Two Isoenzymes of Cutinase and a Nonspecific Esterase from Fusarium solani $\mathrm{f}$. pisi. Biochemistry, 14, 2824-2831. http://dx.doi.org/10.1021/bi00684a006

[4] Kolattukudy, P. (1985) Enzymatic Penetration of the Plant Cuticle by Fungal Pathogens. Annual Review of Phytopathology, 23, 223-250. http://dx.doi.org/10.1146/annurev.py.23.090185.001255

[5] Heredia, A. (2003) Biophysical and Biochemical Characteristics of Cutin, a Plant Barrier Biopolymer. Biochimica et Biophysica Acta (BBA)-General Subjects, 1620, 1-7. http://dx.doi.org/10.1016/S0304-4165(02)00510-X

[6] Lin, T. and Kolattukudy, P. (1978) Induction of a Biopolyester Hydrolase (Cutinase) by Low Levels of Cutin Monomers in Fusarium solani f. sp. pisi. Journal of Bacteriology, 133, 942-951. http://jb.asm.org/content/133/2/942.short

[7] Longhi, S. and Cambillau, C. (1999) Structure-Activity of Cutinase, a Small Lipolytic Enzyme. Biochimica et Biophysica Acta (BBA)-Molecular and Cell Biology of Lipids, 1441, 185-196. http://dx.doi.org/10.1016/S1388-1981(99)00159-6

[8] Chen, S., Su, L., Chen, J. and Wu, J. (2013) Cutinase: Characteristics, Preparation, and Application. Biotechnology Advances, 31, 1754-1767. http://dx.doi.org/10.1016/j.biotechadv.2013.09.005

[9] Egmond, M.R. and de Vlieg, J. (2000) Fusarium solani pisi Cutinase. Biochimie, 82, 1015-1021. http://dx.doi.org/10.1016/S0300-9084(00)01183-4

[10] Li, J., Liu, L., Chen, S., Du, G. and Chen, J. (2009) Advances in Cutinase Research. Chinese Journal of Biotechnology, 25, 1829-1837. http://europepmc.org/abstract/med/20352957

[11] Sebastian, J., Chandra, A. and Kolattukudy, P. (1987) Discovery of a Cutinase-Producing Pseudomonas sp. Cohabiting with an Apparently Nitrogen-Fixing Corynebacterium sp. in the Phyllosphere. Journal of Bacteriology, 169, 131-136. http://jb.asm.org/content/169/1/131.short

[12] Carvalho, C.M., Aires-Barros, M.R. and Cabral, J. (1998) Cutinase Structure, Function and Biocatalytic Applications. Electronic Journal of Biotechnology, 1, 160-173. http://dx.doi.org/10.2225/vol1-issue3-fulltext-8

[13] Carvalho, C.M., Aires-Barros, M.R. and Cabral, J. (1999) Cutinase: From Molecular Level to Bioprocess Development. Biotechnology and Bioengineering, 66, 17-34. http://dx.doi.org/10.1002/(SICI)1097-0290(1999)66:1<17::AID-BIT2>3.0.CO;2-F

[14] Pio, T.F. and Macedo, G.A. (2009) Chapter 4 Cutinases: Properties and Industrial Applications. In: Laskin, I.A., Sariaslani, S. and Geoffrey, M.G., Eds., Advances in Applied Microbiology, Academic Press, Waltham, 77-95. http://www.sciencedirect.com/science/article/pii/S0065216408008046

[15] Vidinha, P., Augusto, V., Almeida, M., Fonseca, I., Fidalgo, A., Ilharco, L., Cabral, J.M. and Barreiros, S. (2006) Sol-Gel Encapsulation: An Efficient and Versatile Immobilization Technique for Cutinase in Non-Aqueous Media. Journal of Biotechnology, 121, 23-33. http://dx.doi.org/10.1016/j.jbiotec.2005.06.018 
[16] Lauwereys, M., De Geus, P., De Meutter, J., Stanssens, P. and Matthyssens, G. (1991) Cloning, Expression and Characterization of Cutinase, a Fungal Lipolytic Enzyme. In: Alberghina, L., Schmid, R.D. and Verger, R., Eds., LipasesStructure, Function and Genetic Engineering, Wiley-VCH, Weinheim, 243-251. http://www.wiley-vch.de/publish/en/company/contact/?sID=v2kgfqie8apmrte0ge7noc68s7

[17] Sagt, C. and Verrips, C. (1995) Secretion of Wild-Type and Mutant Cutinases by Saccharomyces cerevisiae. Yeast, 11, 594.

[18] Degani, O., Gepstein, S. and Dosoretz, C.G. (2002) Potential Use of Cutinase in Enzymatic Scouring of Cotton Fiber Cuticle. Applied Biochemistry and Biotechnology, 102-103, 277-289. http://dx.doi.org/10.1385/ABAB:102-103:1-6:277

[19] Degani, O., Gepstein, S. and Dosoretz, C.G. (2004) A New Method for Measuring Scouring Efficiency of Natural Fibers Based on the Cellulose-Binding Domain- $\beta$-Glucuronidase Fused Protein. Journal of Biotechnology, 107, 265-273. http://dx.doi.org/10.1016/j.jbiotec.2003.10.015

[20] Kim, Y.H., Lee, J., Ahn, J.Y., Gu, M.B. and Moon, S.H. (2002) Enhanced Degradation of an Endocrine-Disrupting Chemical, Butyl Benzyl Phthalate, by Fusarium oxysporum f. sp. pisi Cutinase. Applied and Environmental Microbiology, 68, 4684-4688. http://dx.doi.org/10.1128/AEM.68.9.4684-4688.2002

[21] Pio, T.F. and Macedo, G.A. (2007) Optimizing the Production of Cutinase by Fusarium oxysporum Using Response Surface Methodology. Enzyme and Microbial Technology, 41, 613-619. http://dx.doi.org/10.1016/j.enzmictec.2007.05.008

[22] Kim, Y.H., Seo, H.S., Min, J., Kim, Y.C., Ban, Y.H., Han, K., Park, J.S., Bae, K.D., Gu, M. and Lee, J. (2007) Enhanced Degradation and Toxicity Reduction of Dihexyl Phthalate by Fusarium oxysporum f. sp. pisi Cutinase. Journal of Applied Microbiology, 102, 221-228. http://dx.doi.org/10.1111/j.1365-2672.2006.03095.x

[23] Liang, D.W., Zhang, T., Fang, H.H. and He, J. (2008) Phthalates Biodegradation in the Environment. Applied Microbiology and Biotechnology, 80, 183-198. http://dx.doi.org/10.1007/s00253-008-1548-5

[24] Mao, H., Liu, H., Gao, Z., Su, T. and Wang, Z. (2015) Biodegradation of Poly(butylene succinate) by Fusarium sp. FS1301 and Purification and Characterization of Poly(butylene succinate) Depolymerase. Polymer Degradation and Stability, 114, 1-7. http://dx.doi.org/10.1016/j.polymdegradstab.2015.01.025

[25] Abdel-Motaal, F., El-Sayed, M., El-Zayat, S. and Ito, S.I. (2014) Biodegradation of Poly ( $\varepsilon$-Caprolactone) (PCL) Film and Foam Plastic by Pseudozyma japonica sp. nov., a Novel Cutinolytic Ustilaginomycetous Yeast Species. 3 Biotech, 4, 507-512. http://dx.doi.org/10.1007/s13205-013-0182-9

[26] Degani, O., Salman, H., Gepstein, S. and Dosoretz, C.G. (2006) Synthesis and Characterization of a New Cutinase Substrate, 4-nitrophenyl (16-methyl sulfone ester) Hexadecanoate. Journal of Biotechnology, 121, 346-350. http://dx.doi.org/10.1016/j.jbiotec.2005.08.011

[27] Kolattukudy, P.E., Purdy, R.E. and Maiti, I.B. (1981) Cutinases from Fungi and Pollen. In: John, M.L, Ed., Methods in Enzymology, Academic Press, Waltham, 652-664. http://dx.doi.org/10.1016/0076-6879(81)71078-4

[28] Maizel, J. (1971) Polyacrylamide Gel Electrophoresis of Viral Proteins. Methods in Virology, 5, 179-246. http://dx.doi.org/10.1016/B978-0-12-470205-9.50011-3

[29] Dewald, B., Dulaney, J.T. and Touster, O. (1973) Solubilization and Polyacrylamide Gel Electrophoresis of Membrane Enzymes with Detergents. Methods in Enzymology, 32, 82-91. http://dx.doi.org/10.1016/0076-6879(74)32011-3

[30] Ray, A.K., Lin, Y.Y., Gerard, H., Chen, Z.J., Osman, S.F., Fett, W.F., Moreau, R.A. and Stark, R.E. (1995) Separation and Identification of Lime Cutin Monomers by High Performance Liquid Chromatography and Mass Spectrometry. Phytochemistry, 38, 1361-1369. http://www.sciencedirect.com/science/article/pii/0031942294006276 http://dx.doi.org/10.1016/0031-9422(94)00627-6

[31] Walton, T. and Kolattukudy, P. (1972) Determination of the Structures of Cutin Monomers by a Novel Depolymerization Procedure and Combined Gas Chromatography and Mass Spectrometry. Biochemistry, 11, 1885-1897. http://dx.doi.org/10.1021/bi00760a025

[32] Purdy, R. and Kolattukudy, P. (1975) Hydrolysis of Plant Cuticle by Plant Pathogens. Properties of Cutinase I, Cutinase II, and a Nonspecific Esterase Isolated from Fusarium solani pisi. Biochemistry, 14, 2832-2840. http://dx.doi.org/10.1021/bi00684a007

[33] Soliday, C.L. and Kolattukudy, P.E. (1976) Isolation and Characterization of a Cutinase from Fusarium roseum culmorum and Its Immunological Comparison with Cutinases from F. solani pisi. Archives of Biochemistry and Biophysics, 176, 334-343. http://dx.doi.org/10.1016/0003-9861(76)90172-7

[34] Bonnen, A. and Hammerschmidt, R. (1989) Cutinolytic Enzymes from Colletotrichum lagenarium. Physiological and Molecular Plant Pathology, 35, 463-474. http://dx.doi.org/10.1016/0885-5765(89)90088-X

[35] Hawthorne, B.T., Rees-George, J. and Crowhurst, R.N. (2001) Induction of Cutinolytic Esterase Activity during Saprophytic Growth of Cucurbit Pathogens, Fusarium solani f. sp. Cucurbitae Races One and Two (Nectria haemato- 
cocca MPI and MPV, Respectively). FEMS Microbiology Letters, 194, 135-141. http://dx.doi.org/10.1111/j.1574-6968.2001.tb09458.x

[36] Purdy, R.E. and Kolattukudy, P.E. (1973) Depolymerization of a Hydroxy Fatty Acid Biopolymer, Cutin, by an Extracellular Enzyme from Fusarium solani f. pisi: Isolation and Some Properties of the Enzyme. Archives of Biochemistry and Biophysics, 159, 61-69. http://dx.doi.org/10.1016/0003-9861(73)90429-3

[37] Macedo, G.A. and Pio, T.F. (2005) A Rapid Screening Method for Cutinase Producing Microorganisms. Brazilian Journal of Microbiology, 36, 388-394. http://dx.doi.org/10.1590/S1517-83822005000400016

[38] Petersen, M.T.N., Martel, P., Petersen, E.I., Drablos, F. and Petersen, S.B. (1997) Surface and Electrostatics of Cutinases. Methods in Enzymology, 284, 130-154. http://dx.doi.org/10.1016/S0076-6879(97)84009-8

[39] Sebastian, J. and Kolattukudy, P. (1988) Purification and Characterization of Cutinase from a Fluorescent Pseudomonas putida Bacterial Strain Isolated from Phyllosphere. Archives of Biochemistry and Biophysics, 263, 77-85. http://dx.doi.org/10.1016/0003-9861(88)90615-7

[40] Speranza, P., Carvalho, P.D.O. and Macedo, G.A. (2011) Effects of Different Solid State Fermentation Substrate on Biochemical Properties of Cutinase from Fusarium sp. Journal of Molecular Catalysis B: Enzymatic, 72, 181-186. http://dx.doi.org/10.1016/j.molcatb.2011.06.003 